\title{
An In Planta Method for Assessing the Role of Basidiospores in Rhizoctonia Foliar Disease of Tomato
}

Faith E. Bartz and Marc A. Cubeta, Department of Plant Pathology, North Carolina State University, Raleigh 27695; Takeshi Toda, Faculty of Bioresource Science, Akita Prefectural University, Shimo-shinjo, Akita 010-0195, Japan; Shigeo Naito, Agriculture, Forestry and Fisheries Technical Information Society, Nihonbashi-kabutocho, Chuo-ku, Tokyo 103-0026; and Kelly L. Ivors, Department of Plant Pathology, North Carolina State University, Mountain Horticultural Crops Research \& Extension Center, Mills River 28759

\begin{abstract}
Bartz, F. E., Cubeta, M. A., Toda, T., Naito, S., and Ivors, K. L. 2010. An in planta method for assessing the role of basidiospores in Rhizoctonia foliar disease of tomato. Plant Dis. 94:515-520.

A tomato (Solanum lycopersicum) foliar blight disease of unknown etiology was observed in North Carolina (NC) during 2005 to 2006. Symptoms included necrotic lesions and blighted leaves, with signs of white mycelial growth on abaxial leaf surfaces. The morphology of isolates from symptomatic leaves was consistent with that of Rhizoctonia solani. Because the pattern of symptom expression suggested that basidiospores were the primary inoculum source, Koch's postulates were fulfilled using a method to generate basidiospores in planta. Isolates were characterized by morphology, DNA sequence analysis, hyphal anastomosis, and somatic hyphal interactions. Phylogenetic analyses and hyphal anastomosis criteria support placement of the isolates in $R$. solani anastomosis group 3 (AG-3). Tomato foliar blight isolates from NC form a single phylogenetic group with tomato isolates of $R$. solani AG-3 from Japan and are more closely related to $R$. solani AG-3 isolates from potato than tobacco. Isolates exhibited both compatible and incompatible hyphal interactions when paired in vitro. To our knowledge, this is the first detailed report of tomato foliar blight caused by $R$. solani AG-3 in North America. A comprehensive description of the technique employed for producing basidiospores is presented with potential utility for understanding foliar disease etiology in other Rhizoctonia pathosystems.
\end{abstract}

A foliar blight disease of tomato (Solanum lycopersicum L.) of unknown etiology was observed during 2005 in a commercial field located in Rowan County, North Carolina (NC). This disease was subsequently found in four fields in two additional NC counties (Henderson and Polk) in 2006. The symptoms appeared as brown necrotic lesions and blighted leaves in the mid- to upper canopy (Fig. 1A), and signs of white mycelial growth were observed on the underside of infected leaves (Fig. 1B). Isolates obtained from symptomatic leaf tissue displayed morphological characteristics consistent with that of Rhizoctonia solani Kühn (teleomorph = Thanatephorus cucumeris (A.B. Frank) Donk) (4,31).

$R$. solani is a species complex composed of a diverse assemblage of soil fungi that vary with respect to host specificity, life history, and morphology. Historically,

Corresponding author: K. L. Ivors
E-mail: kelly_ivors@ncsu.edu

GenBank accession no. GQ885147 derived from this study.

Accepted for publication 26 January 2010.

doi:10.1094/PDIS-94-5-0515

(C) 2010 The American Phytopathological Society fungi in this species complex have been based on their somatic hyphal interactions with tester strains. At least 13 AGs of $R$. solani have been recognized $(2,5,6,23)$. More recent analyses of ribosomal RNA and $\beta$-tubulin genes support the traditional AG classification and suggest that the AGs of $R$. solani share a common evolutionary history $(16,17)$. Although fungi in the $R$. solani species complex can cause diseases of more than 500 genera of plants, host range is generally more limited within an AG. For example, $R$. solani AG-3 is predominantly pathogenic on members of the family Solanaceae that include eggplant, placed into anastomosis groups (AGs)

pepper, potato, tobacco, and tomato $(5,14,29)$.

The symptoms of $R$. solani infection on tomato are typically expressed in or near the soil, and include seedling damping-off, root necrosis, basal stem cankers, and fruit rot (20). This pattern of symptom expression results from the colonization of plant tissues by fungal hyphae or sclerotia present in the soil, and often results from splash dispersal of these propagules onto leaves and stems by rain (12). However, numerous foliar diseases of $R$. solani have been reported on other cultivated (e.g., bean, lettuce, soybean, sugar beet, and tobacco) and noncultivated hosts $(12,26,27)$. For these pathosystems, disease results primarily from infection by sexual spores (i.e., basidiospores) which are produced under warm $\left(\geq 20^{\circ} \mathrm{C}\right)$, humid ( $\geq 90 \%$ relative humidity) conditions and often are dispersed in the dark $(26,27)$. There are several examples of foliar diseases caused by $R$. solani AG-3 within the family Solanaceae. Target spot disease of tobacco is attributed to infection by basidiospores of the teleomorph stage of $R$. solani AG-3 (19). Sexual spores of this fungus on potato have been reported to cause leaf lesions, although the role of basidiospores in disease epidemiology is not well understood (27). There is also one published report of tomato foliar blight in Japan caused by $R$. solani AG-3 (13).

The objectives of this study were to (i) verify that $R$. solani was the causal agent of the tomato foliar blight observed in NC from 2005 to 2006 by demonstrating

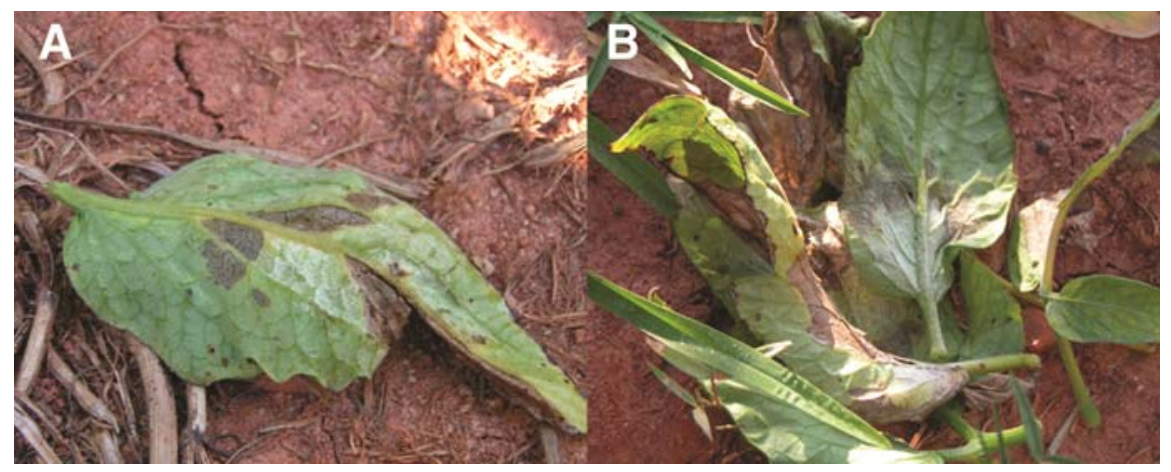

Fig. 1. A, Blight symptoms on a tomato leaf infected by Rhizoctonia solani anastomosis group 3 (AG3 ). B, Necrotic lesions and mycelial growth on abaxial side of $R$. solani AG-3-infected tomato leaves. 
Koch's postulates using a recently developed in planta-based method to produce basidiospores as inoculum and (ii) characterize tomato foliar blight isolates based on phylogenetic analysis of ribosomal DNA (rDNA) sequences and somatic hyphal interaction criteria. A preliminary report of this research has been published (18).

\section{MATERIALS AND METHODS}

Examination of diseased samples and isolation. Leaves from more than 25 plants exhibiting blight symptoms and signs of fungal infection were collected from three tomato cultivars (Mountain Fresh, Crista, and FL 47) from five fields in Rowan, Henderson, and Polk Counties of NC in 2005 to 2006. Disease incidence in each field ranged from 5 to $15 \%$ of the entire planting. Slide mounts of mycelium scraped from the underside of infected leaves were initially examined with a compound microscope to observe morphological characteristics.

Isolations were conducted by aseptically excising $3-\mathrm{mm}^{2}$ sections of leaf from the leading edge of symptomatic tissue. Leaf sections were rinsed in deionized $\mathrm{H}_{2} \mathrm{O}$, embedded in acidified $2 \%$ water agar $(\mathrm{pH}$
6.2), and incubated at $25^{\circ} \mathrm{C}$ in the dark. Isolates were transferred to potato dextrose agar (PDA) (Difco Laboratories, Detroit) and incubated at $25^{\circ} \mathrm{C}$ to establish pure cultures. A preliminary identification of each isolate was made based on both macroscopic and microscopic characteristics of fungal structures and mycelium. Twenty isolates with hyphal and nuclear characteristics of $R$. solani were isolated and stored for further examination in this study (Table 1). Plugs of mycelia, $5 \mathrm{~mm}$ in diameter, were taken from $1 \mathrm{~cm}$ behind the leading edge of the colony and placed in 2.0-ml cryogenic vials (Corning, Corning, NY) containing $500 \mu$ l of potato dextrose broth (PDB; Difco Laboratories) and incubated for $48 \mathrm{~h}$ at $25^{\circ} \mathrm{C}$. A $500-\mu \mathrm{l}$ aliquot of sterile $50 \%$ glycerol (Sigma-Aldrich, St. Louis) was added to each cryogenic vial before storing at $-80^{\circ} \mathrm{C}$.

Isolate characterization by DNA sequencing and phylogenetic analyses. Sequence analysis of the internal transcribed spacer (ITS) regions of the rDNA repeat as well as anastomosis criteria were used to determine the AG identity of the isolates of $R$. solani $(5,16,30)$. The ITS rDNA sequences were obtained for six isolates: Tom7b, Tom19a, Tom21f, Tom22a, Tom23a, and Tom23e. For each isolate, three plugs ( $5 \mathrm{~mm}$ in diameter) of actively growing mycelium on PDA were transferred to a $10-\mathrm{cm}$-diameter petri dish containing $15 \mathrm{ml}$ of PDB and incubated at $25^{\circ} \mathrm{C}$ in the dark for 5 to 7 days, until colonies had reached the edge of the dish. The mycelia were separated from the broth by vacuum filtration onto Whatman no. 1 filter paper (Whatman International, Ltd., England) and frozen at $-80^{\circ} \mathrm{C}$. The frozen mycelium of each isolate was ground in liquid nitrogen (Airgas National Welders, Morrisville, NC) with a mortar and pestle.

DNA was extracted from the ground, frozen mycelium using the DNeasy Plant Mini Kit (Qiagen, Germantown, MD). The following modifications were made to the manufacturer's protocol for extraction from fungal tissue: $100 \mu \mathrm{l}$ of diamond beads were added to each tube along with buffer AP1 and RNase to facilitate cell lysis, and elution was carried out using 50 $\mu \mathrm{l}$ of sterile deionized water. DNA was stored at $-20^{\circ} \mathrm{C}$ until amplified by the polymerase chain reaction (PCR). Reactions for PCR amplification were prepared in a total volume of $25 \mu \mathrm{l}$ comprising $1 \mu \mathrm{l}$

Table 1. Source, anastomosis group (AG), and accession numbers of sequences deposited for isolates of Rhizoctonia solani used in this study

\begin{tabular}{|c|c|c|c|c|}
\hline Isolate $^{a}$ & Host & Location & AG, subgroup & GenBank accession number ${ }^{b}$ \\
\hline Tom7a & Tomato cv. Mountain Fresh & Rowan Co, NC & AG-3 & N/A \\
\hline Tom7b & Tomato cv. Mountain Fresh & Rowan Co., NC & AG-3 & GQ885147 \\
\hline Tom7c & Tomato cv. Mountain Fresh & Rowan Co., NC & AG-3 & N/A \\
\hline Tom19a & Tomato cv. Crista & Polk Co., NC & AG-3 & * \\
\hline Tom19b & Tomato cv. Crista & Polk Co., NC & AG-3 & N/A \\
\hline Tom21a & Tomato cv. Mountain Fresh & Henderson Co., NC & AG-3 & N/A \\
\hline Tom $21 b$ & Tomato cv. Mountain Fresh & Henderson Co., NC & AG-3 & N/A \\
\hline Tom21c & Tomato cv. Mountain Fresh & Henderson Co., NC & AG-3 & N/A \\
\hline Tom $21 \mathrm{~d}$ & Tomato cv. Mountain Fresh & Henderson Co., NC & AG-3 & N/A \\
\hline Tom21e & Tomato cv. Mountain Fresh & Henderson Co., NC & AG-3 & N/A \\
\hline Tom21f & Tomato cv. Mountain Fresh & Henderson Co., NC & AG-3 & $*$ \\
\hline Tom $21 \mathrm{~g}$ & Tomato cv. Mountain Fresh & Henderson Co., NC & AG-3 & N/A \\
\hline Tom22a & Tomato cv. Crista & Polk Co., NC & AG-3 & N/A \\
\hline Tom $22 b$ & Tomato cv. Crista & Polk Co., NC & AG-3 & N/A \\
\hline Tom22c & Tomato cv. Crista & Polk Co., NC & AG-3 & N/A \\
\hline Tom23a & Tomato cv. FL 47 & Henderson Co., NC & AG-3 & * \\
\hline Tom23b & Tomato cv. FL 47 & Henderson Co., NC & AG-3 & N/A \\
\hline Tom $23 \mathrm{c}$ & Tomato cv. FL 47 & Henderson Co., NC & AG-3 & N/A \\
\hline Tom23d & Tomato cv. FL 47 & Henderson Co., NC & AG-3 & N/A \\
\hline Tom $23 \mathrm{e}$ & Tomato cv. FL 47 & Henderson Co., NC & AG-3 & * \\
\hline OKA-6 & Tomato & Japan & AG-3 & AB000023 \\
\hline OKA-9 & Tomato & Japan & AG-3 & AB000024 \\
\hline 1 & Tobacco & United States & AG-3 & AB000001 \\
\hline 30 & Tobacco & United States & AG-3 & AB000002 \\
\hline 1600 & Tobacco & United States & AG-3 & AB000004 \\
\hline 1614 & Tobacco & United States & AG-3 & $\mathrm{AB} 000005$ \\
\hline 4Rs (ATCC 14006) & Potato & United States & AG-3 & AF354064 \\
\hline 5Rs (ATCC 44660) & Potato & United States & AG-3 & AF354107 \\
\hline 6Rs (ATCC 14701) & Potato & United States & AG-3 & AF354106 \\
\hline ST3-1 & Potato & Japan & AG-3 & AB000041 \\
\hline ST4-1 & Potato & Japan & AG-3 & AB000042 \\
\hline ST6-3 & Potato & Japan & AG-3 & AB000043 \\
\hline Rhs1AP (ATCC MYA-4579) & Potato & Maine & AG-3 & N/A \\
\hline Rs161 & Potato & Hyde Co., NC & AG-3 & N/A \\
\hline AH-1 (ATCC 76126) & Peanut & Japan & AG-4 & N/A \\
\hline Rh-165 (ATCC 76127) & Sugar beet & Japan & AG-4 & N/A \\
\hline 2Rs (ATCC 66158) & Rice & United States & AG-1-IA & AF354097 \\
\hline
\end{tabular}

a Isolate names with the prefix "Tom" represent those isolated in this study. "Tom" isolates with the same number originated from the same plant but different leaves (a, b, c, and so on).

${ }^{\mathrm{b}}$ GenBank accession number with the prefix "GQ" represents isolate sequenced in this study, N/A = not available, and * = sequence determined in this study to be identical to that of GenBank accession number GQ885147. 
of extracted DNA, $1 \mu \mathrm{l}$ each of $10 \mu \mathrm{M}$ solutions of primers ITS5 and ITS4b (Integrated DNA Technologies, Coralville, IA), $12.5 \mu \mathrm{l}$ of $2 \times$ PCR master mix (Fermentas, Glen Burnie, MD), and $9.5 \mu \mathrm{l}$ of DNasefree water (Fermentas) (15,36). Amplifications were performed with a Mastercycler epgradient $\mathrm{S}$ model thermal cycler (Eppendorf, Westbury, NY). The cycle parameters were an initial denaturation at $96^{\circ} \mathrm{C}$ for $5 \mathrm{~min}$ followed by 30 cycles of denaturation at $96^{\circ} \mathrm{C}$ for $1 \mathrm{~min}$, annealing at $55^{\circ} \mathrm{C}$ for $1 \mathrm{~min}$, and extension at $72^{\circ} \mathrm{C}$ for $2 \mathrm{~min}$. A final extension period at $72^{\circ} \mathrm{C}$ was held for $7 \mathrm{~min}$. A UV transilluminator was used to visualize PCR products. The reaction products were purified with the QIAquick PCR purification kit according to the manufacturer's spin protocol.

PCR-purified product ( $2 \mu \mathrm{l}$ for each isolate) was inserted into a pCR 2.1 vector using the Invitrogen TOPO TA cloning kit (Invitrogen, Carlsbad, CA) with the following modification to manufacturer's specifications: $0.5 \mu \mathrm{l}$ of TOPO vector was added to $5.5 \mu$ l of total volume of each cloning reaction mixture. Vectors were transformed into One Shot TOP10 chemically competent Escherichia coli (Invitrogen). Three transformant colonies were picked per isolate and grown in LuriaBertani broth at $37^{\circ} \mathrm{C}$ for $24 \mathrm{~h}$. Pellets of bacterial cells were formed by centrifuging the overnight $E$. coli cultures at 3,000 rpm for $20 \mathrm{~min}$ at $4^{\circ} \mathrm{C}$. The supernatant was discarded and the pellets were stored at $-20^{\circ} \mathrm{C}$. The vector was extracted from the E. coli cells using the Qiaprep Spin Miniprep Kit (Qiagen). The cloned ITS regions were amplified from the vectors using PCR with dye terminator chemistry. Reaction mixtures contained $7 \mu \mathrm{l}$ of a 1:15 dilution of the vector, $0.5 \mu$ l of BigDye v.3.1 cycle sequencing terminator (Applied Biosystems, Foster City, CA), $1.5 \mu \mathrm{l}$ of BigDye sequencing buffer (Applied Biosystems), and $1 \mu \mathrm{l}$ of $10 \mu \mathrm{M}$ M13 primer solution (Integrated DNA Technologies). Vector map and primer sequences are available through Invitrogen. The sequencing PCR parameters were an initial denaturation at $96^{\circ} \mathrm{C}$ for 2 min followed by 30 cycles of denaturation at $96^{\circ} \mathrm{C}$ for $30 \mathrm{~s}$, annealing at $50^{\circ} \mathrm{C}$ for $15 \mathrm{~s}$, and extension at $60^{\circ} \mathrm{C}$ for $4 \mathrm{~min}$. The sequences were determined using an Applied Biosytems 3730xl DNA analyzer (Applied Biosystems). Accuracy of ITS sequences obtained in this study was confirmed by comparison with those deposited in GenBank, and one representative sequence was deposited in GenBank (Table 1).

Sequences were compared with those published by Gonzalez et al. (16) for $R$. solani AG-3 isolates from potato, tobacco, and tomato, with an isolate of $R$. solani AG1-1A from rice included as an outgroup taxon. Sequences were aligned using the ClustalW2 software program (European Bioinformatics Institute, Cambridge, UK) and manually edited using MacClade software to exclude ambiguous regions (Sinauer Associates, Inc. Publishers, Sunderland, MA) (21). The maximum likelihood criterion in Phylogenetic Analysis Using Parsimony (PAUP) was used for the phylogenetic analysis, which included a heuristic search using random stepwise sequence addition with 1,000 replicates (32). The outgroup taxon was defined before calculating bootstrap values from 1,000 replicates.

Isolate characterization by hyphal anastomosis. The putative identity of tomato foliar blight isolates Tom7b, Tom7c, Tom19a, Tom21f, Tom22a, Tom23a, and Tom $23 \mathrm{~b}$ was confirmed by pairing with representative AG-3 tester isolates (Rhs1AP [ATCC MYA-4579] and Rs161). Tomato foliar blight isolates Tom7b and Tom7c were also paired with representative AG-4 tester isolates (AH-1 [ATCC 76126] and Rh-165 [ATCC 76127]). The anastomosis interaction was also observed between 12 of the tomato foliar blight isolates paired with each other. Microscopic examination of hyphal interactions followed the technique described by Carling (5) and nuclear staining was performed with phenosafranin (SigmaAldrich) (30). For each paired isolate, one mycelial plug (5 $\mathrm{mm}$ in diameter) was taken from $1 \mathrm{~cm}$ behind the leading edge of an actively growing colony on PDA and was placed on the upper surface of a glass slide coated with $2 \%$ water agar. The plugs of paired isolates were placed $3 \mathrm{~cm}$ apart on each slide. Three replicate slides were prepared for each pairing, and each isolate was paired with itself as a control. A plastic box containing the slides and a moist paper towel was covered and incubated in the dark at $25^{\circ} \mathrm{C}$ for 24 to $48 \mathrm{~h}$. When the mycelia of the paired isolates grew together, the hyphae were stained to enable visualization of the contact zone with one drop each of aqueous solutions of $0.1 \%$ phenosafranin and 3\% potassium hydroxide (Sigma-Aldrich). Each slide was observed using a light microscope at $\times 100$ and $\times 400$ magnification. Anastomosis reactions were scored based on the categories defined by Carling et al. $(5,7)$.

Isolate characterization by macroscopic somatic hyphal interactions. Tomato foliar blight isolates were paired on petri plates containing $30 \mathrm{ml}$ of PDA with $1 \%$ activated charcoal (3) and examined for their resulting somatic hyphal interactions as described by MacNish et al (22). Self-pairings were used as controls and three replicate plates were prepared per pairing. Plates were incubated at $25^{\circ} \mathrm{C}$ in the dark for 5 to 7 days and somatic hyphal interactions were scored as compatible or incompatible as described by Charlton and Cubeta (11).

Demonstration of pathogenicity. Tomato plants (cv. Mountain Fresh) were grown in a $22^{\circ} \mathrm{C}$ growth chamber in pots
(10 $\mathrm{cm}$ in diameter and $7 \mathrm{~cm}$ deep) containing 2:2:1 potting mix of pine bark:peat moss:vermiculite supplemented with lime. The chamber was illuminated by $40-\mathrm{W}$ cool, white fluorescent bulbs set to a photoperiod of $12 \mathrm{~h}$ of light. Plants were watered as needed with deionized $\mathrm{H}_{2} \mathrm{O}$. Inoculum was produced for pathogenicity experiments on tomato using the following procedures. Isolates Tom7b, Tom19a, Tom21f, Tom22a, Tom23a, Tom23c, and Tom23e were retrieved from cryogenic preservation and grown on PDA at $25^{\circ} \mathrm{C}$ in the dark for 4 to 5 days. For each isolate, four 5-mm-diameter mycelial plugs were added to a 100-ml glass jar containing $20 \mathrm{~g}$ of sterile oat grains. The oat grains had been moistened by $20 \mathrm{ml}$ of deionized $\mathrm{H}_{2} \mathrm{O}$ before autoclaving. The oat grain inocula were incubated at $25^{\circ} \mathrm{C}$ in the dark for at least 10 days, until the grains were fully colonized. Ten colonized oat grains were placed approximately $1 \mathrm{~cm}$ deep in the soil around the base of each 3- to 4-week-old tomato plant. Both single isolates and 17 representative pairs of isolates were added to the soil of a single tomato plant for each treatment. When isolates were paired, soil was amended with five colonized oat grains of each isolate. Each plant was placed in a clear plastic box and sprayed with deionized $\mathrm{H}_{2} \mathrm{O}$ as needed to maintain high humidity. When mycelial growth was observed on stem tissue, tape mounts were stained with lactophenol blue as described by Millar (24) and observed microscopically for basidia at $\times 400$ magnification.

When basidia or basidial initials on infected tomato stem tissue were observed, this tissue was used to inoculate healthy 4to 5-week-old tomato plants using the following procedure. Stem sections 4 to 8 $\mathrm{cm}$ long were excised aseptically from the leading edge of symptomatic stem tissue with a scalpel and taped to the inner lid of a plastic box above a healthy tomato plant. The stem tissue remained taped to the lid for the duration of the experiment, allowing the basidiospores to forcibly eject onto the leaf tissue. Each plant was then sprayed with deionized $\mathrm{H}_{2} \mathrm{O}$ after inoculation and incubated in the dark for $25 \mathrm{~h}$ before resuming the 12-h photoperiod. Reisolation from symptomatic leaf tissue, which occurred from 4 to 10 days after inoculation, was carried out as described above for the original isolations from field samples. Reisolated cultures were checked for somatic compatibility with the isolates used to generate inoculum on PDA with $1 \%$ activated charcoal as described above. This experiment was conducted twice.

\section{RESULTS}

Examination of diseased samples and isolation. Tape mounts of symptomatic leaf tissue contained multinucleate, hyaline-to-brown hyphae 5 to $13 \mu \mathrm{m}$ wide, without clamp connections, typically with slight constrictions at branch points, and 
with dolipore septa. Aggregations of monilioid cells, 25 to 50 by 15 to $30 \mu \mathrm{m}$, formed loose, cream to brown sclerotia on plant tissue and in culture. In culture, the mycelium was white to various shades of brown and with or without aerial hyphae. Tape mounts of the mycelium on the base of inoculated plants revealed hyphae matching the description of the original field isolates, as well as holobasidia of the teleomorph. Basidia were 15 by 8 to 10 $\mu \mathrm{m}$, discontinuously distributed on short hyphal branches arising from a basal hyphal layer, hyaline, barrel-shaped or subcylindrical, and typically had four sterigmata. Sterigmata were typically broader at the base than at the tip, and 5 to 13 by 2 to $4 \mu \mathrm{m}$. Basidiospores were 4 to 7 by 4 to 5 $\mu \mathrm{m}$, smooth, hyaline, oblong to ellipsoid, unilaterally flattened, and prominently

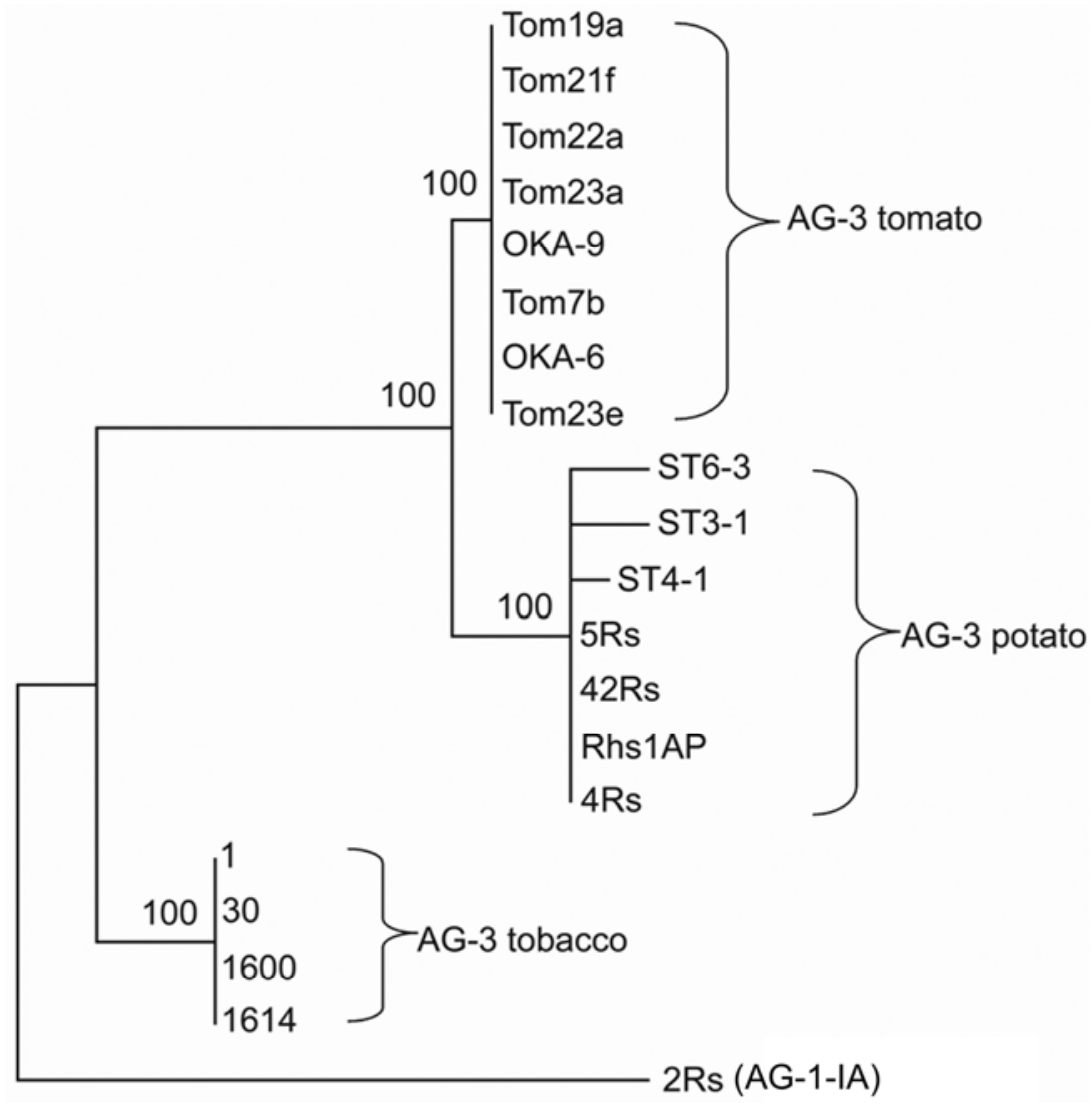

\section{-1 change}

Fig. 2. Consensus tree based on phylogenetic analyses with Phylogenetic Analysis Using Parsimony (32) of internal transcribed spacer (ITS) regions of ribosomal DNA (rDNA) from tomato foliar blight isolates and other isolates of Rhizoctonia solani anastomosis group 3 (AG-3), with an AG-1-IA isolate defined as the outgroup taxon. Branch lengths indicate the number of nucleotide changes between the sequences of each isolate. The relative support for each clade is indicated by bootstrap values on branches. apiculate. This morphology is consistent with that of $R$. solani and teleomorph $T$. cucumeris $(4,31)$.

Isolate characterization by DNA sequencing and phylogenetic analyses. Because all ITS rDNA sequences generated for the tomato foliar blight isolates characterized in this study were identical, only one sequence (862 nucleotides in length) was submitted to GenBank. Based on phylogenetic relatedness, the $\mathrm{NC}$ tomato foliar blight isolates formed a single group with other isolates of $R$. solani AG-3 from tomato in Japan (Fig. 2). All tomato isolates were more closely related to isolates of $R$. solani AG-3 from potato than tobacco. When an expanded phylogeny was created, the tomato foliar blight isolates grouped together with members of $R$. solani AG-3 and separately from members of all other $R$. solani AGs (data not shown).

Isolate characterization by hyphal anastomosis. All tomato foliar blight isolates paired with $R$. solani AG-3 tester isolates Rhs1AP and Rs161 showed a C2 interaction, with anastomosis followed by cell death as described by Carling (data not shown; 5). All self-pairings displayed a C3 interaction, with fusion of cell walls and cytoplasm that did not result in cell death. No anastomoses were observed between tomato foliar blight isolates and AG-4 tester isolates (data not shown). This supports the placement of these isolates in AG-3. The anastomosis reactions observed between 12 of the tomato foliar blight isolates paired with each other were either $\mathrm{C} 2$ or C3 (data not shown). These results support the placement of all tomato foliar blight isolates within the same AG.

Isolate characterization by macroscopic somatic hyphal interactions. Tomato foliar blight isolates showed both compatible and incompatible somatic interactions when paired on PDA with $1 \%$ activated charcoal (Table 2). All selfpairings displayed a compatible somatic interaction. Data for somatic hyphal interactions were congruent with data for anastomosis interactions. Paired isolates that displayed a compatible somatic interaction

Table 2. Macroscopic interaction between paired tomato foliar blight isolates of Rhizoctonia solani anastomosis group 3 on potato dextrose agar with $1 \%$ activated charcoal $^{\mathrm{a}}$

\begin{tabular}{|c|c|c|c|c|c|c|c|c|c|c|c|c|}
\hline Isolates & Tom7c & Tom19a & Tom19b & Tom21f & Tom22a & Tom22b & Tom22c & Tom23a & Tom23b & Tom23c & Tom23d & Tom23e \\
\hline Tom7c & + & - & - & + & + & + & + & - & - & + & - & - \\
\hline Tom19a & $\ldots$ & + & + & - & - & - & - & - & - & - & - & - \\
\hline Tom 19b & $\ldots$ & $\ldots$ & + & - & - & - & - & - & - & - & - & - \\
\hline Tom21f & $\ldots$ & $\ldots$ & $\ldots$ & + & + & + & + & - & - & + & - & - \\
\hline Tom22a & $\ldots$ & $\ldots$ & $\ldots$ & $\ldots$ & + & + & + & - & - & + & - & - \\
\hline Tom22b & $\ldots$ & $\ldots$ & $\ldots$ & $\ldots$ & $\ldots$ & + & + & - & - & + & - & - \\
\hline Tom22c & $\ldots$ & $\ldots$ & $\ldots$ & $\ldots$ & $\ldots$ & $\ldots$ & + & - & - & + & - & - \\
\hline Tom $23 a$ & $\ldots$ & $\ldots$ & $\ldots$ & $\ldots$ & $\ldots$ & $\ldots$ & $\ldots$ & + & - & - & - & + \\
\hline Tom $23 b$ & $\ldots$ & $\ldots$ & $\ldots$ & $\ldots$ & $\ldots$ & $\ldots$ & $\ldots$ & $\ldots$ & + & - & + & - \\
\hline Tom $23 \mathrm{c}$ & $\ldots$ & $\ldots$ & $\ldots$ & $\ldots$ & $\ldots$ & $\ldots$ & $\ldots$ & $\ldots$ & $\ldots$ & + & - & - \\
\hline Tom $23 d$ & $\ldots$ & $\ldots$ & $\ldots$ & $\ldots$ & $\ldots$ & $\ldots$ & $\ldots$ & $\ldots$ & $\cdots$ & $\ldots$ & + & - \\
\hline Tom23e & $\ldots$ & $\ldots$ & $\ldots$ & $\ldots$ & $\ldots$ & $\ldots$ & $\ldots$ & $\ldots$ & $\ldots$ & $\ldots$ & $\ldots$ & + \\
\hline
\end{tabular}

\footnotetext{
${ }^{a}$ Interaction categories: $+=$ somatic compatibility showing merging reaction in the hyphal interaction zone between two paired colonies and $-=$ somatic
} incompatibility showing border line in the hyphal interaction zone between paired isolates $(11,22)$. 
also displayed a C3 microscopic anastomosis interaction, and isolates that displayed an incompatible somatic interaction also displayed a $\mathrm{C} 2$ anastomosis interaction, with one exception. The pairing between isolates Tom19A and Tom $21 \mathrm{~F}$ displayed an incompatible somatic interaction but a C3 anastomosis interaction.

Demonstration of pathogenicity. Mycelia were observed on tomato stem tissue in the growth chamber within 5 to 7 days after inoculation of soil with colonized oat grains, whereas basidia and basidiospores were observed on stems 2 weeks after inoculation. When infected tomato stem tissue with basidia was used to inoculate healthy tomato plants, necrosis and blighting of leaves similar to that observed in the field appeared within 2 weeks. Symptoms began as small, circular necrotic lesions 5 to $15 \mathrm{~mm}$ in diameter, often with targetlike zonation. As the lesions expanded, they appeared water soaked with irregular borders, eventually causing disintegration of leaf tissue. Entire leaf blighting was also observed. Cultures reisolated from symptomatic leaf tissue were morphologically similar to and somatically compatible with the isolates used to generate inoculum. This technique was successful for inoculations with both single and paired isolates in repeated runs of the experiment.

\section{DISCUSSION}

Morphological characteristics of the tomato foliar blight isolates indicated that $R$. solani AG-3 was the causal agent of this disease. However, the typical symptoms of $R$. solani infection on this host do not include foliar blight, which has been reported only once from Japan $(13,20)$. Blighting of tomato leaves under natural conditions in the field did not occur on the lower foliage but was only observed in the mid- to upper canopy. This location is unlikely to be reached by splash-dispersed sclerotia or mycelial fragments from the soil surface. This pattern of symptom expression was most likely the result of infection by aerially dispersed basidiospores of the teleomorph of $R$. solani AG-3.

Although basidiospores are believed to be the primary inoculum for several foliar diseases caused by $R$. solani, their role as infective propagules seldom has been confirmed empirically. Sexual spores are rarely used as inoculum in pathogenicity studies because previously described techniques to induce basidia and basidiospore formation may not be effective for certain isolates of $R$. solani $(1,28,33,35)$. However, the use of basidiospores as inoculum would increase the applicability to natural field situations for investigations into pathosystems where sexual spores are known to play a role in the disease.

In order to accurately demonstrate Koch's postulates for this foliar pathogen, a novel method was developed for the production of basidiospore inoculum on tomato stems. Few experimental protocols currently exist to induce the sexual stage of $R$. solani AG-3 under controlled laboratory conditions (8). Attempts to induce the sexual stage of tomato foliar blight isolates using previously described methods such as the nutrient step-down and soil over culture methods were unsuccessful (data not shown) $(1,28,33,35)$. The method developed in this study is a modification of the technique used by Naito for $R$. solani AG-2-2 on sugar beet (25). This technique was successfully used to induce basidiospore production of at least three different isolates of $R$. solani AG-3 and to demonstrate their pathogenicity on tomato. This in planta method may potentially be useful for producing the teleomorph of other isolates of $R$. solani when demonstrating pathogenicity.

Phylogenetic analysis of ITS rDNA sequences grouped tomato foliar blight isolates from NC together with tomato isolates from Japan and separate from $R$. solani AG-3 potato and tobacco isolates from NC. The isolates analyzed in this study were differentiated based on host rather than geography, despite the fact that several $R$. solani AG-3 potato isolates caused damping off and canker diseases on tomato in greenhouse pathogenicity trials (data not shown). This agrees with the results obtained by other investigators, which have indicated subdivision within populations of $R$. solani AG-3 based on host specificity $(9,10,19)$. The $R$. solani AG-3 tomato isolate subgroup identified in this study was more closely related to isolates from potato than those from tobacco. This is interesting given that the epidemiology of the tomato isolates is more similar to those from tobacco, which also infect the foliage of their host via aerially dispersed basidiospores. This phylogenetic separation of potato and tobacco isolates has been shown in previous studies, and supports the conclusion that tobacco isolates are not pathogenic on potato and vice versa $(9,19)$. The identity of the tomato foliar blight isolates as $R$. solani AG-3 is supported by ITS rDNA sequences, traditional hyphal anastomosis tests, and nuclear staining. Although the ITS rDNA sequences of the tomato isolates from $\mathrm{NC}$ were identical, the observation of incompatible macroscopic somatic interactions indicates that they are probably not of clonal origin.

It is not known whether $R$. solani AG-3 has a homothallic or heterothallic mating system (34). For this reason, inocula consisting of both single and paired foliar blight isolates were used in various combinations when attempting to induce the sexual stage on tomato stems in this study. Basidia were formed on plants inoculated with both single and paired isolates, and basidiospores from both types of treatments were capable of causing infections. Cultures reisolated from symptomatic leaf tissue were tested for somatic compatibility with the isolates used to generate inoculum. In all cases when basidiospores were formed from a paired isolate inoculation, the reisolated culture was somatically compatible with only one of the two progenitor isolates (data not shown). These results indicate that the isolates used in this study do not require a compatible mating partner to initiate meiosis. However, a more thorough study would be necessary to adequately address the hypothesis that the fungi belonging to $R$. solani AG-3 have a homothallic mating system.

Tomato foliar blight disease symptoms and signs were observed when weather conditions were warm and humid, providing extended periods of leaf wetness on tomato plants in fields that had not received preventative fungicide applications. However, additional studies are required to determine the effects of environmental variables on symptom expression and the specific climatic conditions required for disease development. When healthy tomato plants were inoculated with field isolates under controlled conditions in the growth chamber, disease symptoms developed that were similar to those originally observed in the field. During pathogenicity experiments, symptoms first appeared as small, necrotic lesions, often with a targetlike appearance, eventually expanding to cause entire leaf blighting and disintegration. Leaf blighting was observed in the field without small, necrotic target lesions. It was likely that blight symptoms developed from coalesced target spot lesions that were not seen due to the timing of symptom observation in the field. Therefore, more observations are required to determine the range of symptoms for this disease and the temporal sequence of their expression under natural field conditions. To our knowledge, this is the first comprehensive report of tomato foliar blight caused by Rhizoctonia solani AG-3 in North America.

\section{ACKNOWLEDGMENTS}

We thank M. Lancaster for observing and collecting the original samples, D. Milks for her invaluable assistance with inoculation and isolation, M. Rodriguez-Carres for sharing her expertise regarding sequencing and phylogenetic analysis, $\mathrm{L}$. Bukovnik and the sequencing facility at the Duke Institute for Genome Sciences and Policy, and the NC Tomato Growers Association and United States Department of Agriculture CSREES (grants 2007 $34500-15893$ and 2008-34500-19396 to M. A. Cubeta) for financial support.

\section{LITERATURE CITED}

1. Adams, G. C., Jr., and Butler, E. E. 1983 Influence of nutrition on the formation of basidia and basidiospores in Thanatephorus $\mathrm{cu}$ cumeris. Phytopathology 73:147-151.

2. Anderson, N. A. 1982. The genetics and pathology of Rhizoctonia solani. Annu. Rev. Phytopathol. 20:329-347.

3. Butler, E. E., and Bolkan, H. 1973. A medium for heterokaryon formation in Rhizoctonia solani. Phytopathology 63:542-543.

4. Butler, E. E., and Bracker, C. E. 1970. Mor- 
phology and cytology of Rhizoctonia solani. Pages 32-51 in: Rhizoctonia solani, Biology and Pathology. J. R. Parmeter, Jr., ed. University of California Press, Berkeley and Los Angeles.

5. Carling, D. E. 1996. Grouping in Rhizoctonia solani by hyphal anastomosis reaction. Pages 37-47 in: Rhizoctonia Species: Taxonomy, Molecular Biology, Ecology, Pathology and Disease Control. B. Sneh, S. Jabaji-Hare, S. Neate, and G. Dijst, eds. Kluwer Academic Publishers, Dordrecht, The Netherlands.

6. Carling, D. E., Baird, R. E., Gitaitis, R. D., Brainard, K. A., and Kuninaga, S. 2002. Characterization of AG-13, a newly reported anastomosis group of Rhizoctonia solani. Phytopathology 92:893-899.

7. Carling, D. E., Kuninaga, S., and Leiner, R. H. 1988. Relatedness within and among intraspecific groups of Rhizoctonia solani - a comparison of grouping by anastomosis and by DNA hybridization. Phytoparasitica 16:209210.

8. Carling, D. E., and Sumner, D. R. 1992. Rhizoctonia. Pages 157-165 in: Methods for Research on Soilborne Phytopathogenic Fungi. L. L. Singleton, J. D. Mihail, and C. M. Rush, eds. American Phytopathological Society Press, St. Paul, MN.

9. Ceresini, P. C., Shew, H. D., James, T. Y., Vilgalys, R. J., and Cubeta, M. A. 2007. Phylogeography of the Solanaceae-infecting $\mathrm{Ba}$ sidiomycota fungus Rhizoctonia solani AG-3 based on sequence analysis of two nuclear DNA loci. BMC Evol. Biol. 7:163.

10. Ceresini, P. C., Shew, H. D., Vilgalys, R. J., and Cubeta, M. A. 2002. Genetic diversity of Rhizoctonia solani AG-3 from potato and tobacco in North Carolina. Mycologia 94:437449.

11. Charlton, N. D., and Cubeta, M. A. 2007. Transmission of the M2 double-stranded RNA in Rhizoctonia solani anastomosis group 3 (AG-3). Mycologia 99:859-867.

12. Cubeta, M. A., and Vilgalys, R. J. 2000. Rhizoctonia. Pages 109-116 in: Encyclopedia of Microbiology, Vol. 4. J. Lederberg, ed. Academic Press, San Diego, CA

13. Date, H., Yagi, S., Okamoto, Y., and Oniki, N. 1984. On the leaf blight of tomatoes by Thanatephorus cucumeris (Frank) Donk (Rhizoctonia solani). Ann. Phytopathol. Soc. Jpn. 50:399.

14. Farr, D. F., Bills, G. F., Chamuris, G. P., and Rossman, A. Y. 1989. Fungi on Plants and Plant Products in the United States. American Phytopathological Society Press, St. Paul, MN.

15. Gardes, M., and Bruns, T. D. 1993. ITS primers with enhanced specificity for Basidiomycetes-application to the identification of mycorrhizae and rusts. Mol. Ecol. 2:113-118.

16. González, D., Carling, D. E., Kuninaga, S., Vilgalys, R., and Cubeta, M. A. 2001. Ribosomal DNA systematics of Ceratobasidium and Thanatephorus with Rhizoctonia anamorphs. Mycologia 93:1138-1150.

17. González, D., Cubeta, M. A., and Vilgalys, R. 2006. Phylogenetic utility of indels within ribosomal DNA and -tubulin sequences from fungi in the Rhizoctonia solani species complex. Mol. Phylogenet. Evol. 40:459-470.

18. Ivors, K. L., Bartz, F. E., Toda, T., Naito, S., and Cubeta, M. A. 2009. First report of tomato foliar blight caused by Rhizoctonia solani AG3 basidiospore infection in North America. (Abstr.) Phytopathology 99:S57.

19. Johnk, J. S., Jones, R. K., Shew, H. D., and Carling, D. E. 1993. Characterization of populations of Rhizoctonia solani AG-3 from potato and tobacco. Phytopathology 83:854-858.

20. Jones, J. B., Jones, J. P., Stall, R. E., and Zitter, T. A. 1991. Compendium of Tomato Diseases. American Phytopathological Society Press, St. Paul, MN.

21. Larkin, M. A., Blackshields, G., Brown, N. P., Chenna, R., McGettigan, P. A., McWilliam, H., Valentin, F., Wallace, I. M., Wilm, A., Lopez, R., Thompson, J. D., Gibson, T. J., and Higgins, D. G. 2007. Clustal W and Clustal X version 2.0. Bioinformatics 23:2947-2948.

22. MacNish, G. C., Carling, D. E., and Brainard, K. A. 1997. Relationship of microscopic and macroscopic vegetative reactions in Rhizoctonia solani and the occurrence of vegetatively compatible populations (VCPs) in AG-8. Mycol. Res. 101:61-68.

23. Matsumoto, T., Yamamoto, W., and Hirane, S. 1932. Physiology and parasitism of the fungi generally referred to as Hypochnus sasakii Shirai. I. Differentiation of the strains by means of hyphal fusion and culture in differential media. J. Soc. Trop. Agric. 4:370-388.

24. Millar, R. L. 1966. General laboratory proce- dures. Am. Biol. Teach. 28:492-502.

25. Naito, S. 1984. Studies on foliage blight of sugar beet. Res. Bull. Hokkaido Natl. Exp. Stn. 139:145-188.

26. Naito, S. 1996. Basidiospore dispersal and survival. Pages 197-205 in: Rhizoctonia Species: Taxonomy, Molecular Biology, Ecology, Pathology and Disease Control. B. Sneh, S Jabaji-Hare, S. Neate, and G. Dijst, eds. Kluwer Academic Publishers, Dordrecht, The Netherlands.

27. Naito, S. 2006. Ecological studies on teleomorphic and anamorphic stages in Rhizoctonia fungi. J. Gen. Plant Pathol. 72:400-403.

28. Ogoshi, A. 1972. On the perfect stage of anastomosis group AG-2 of Rhizoctonia solani Kühn. Trans. Mycol. Soc. Jpn. 13:285-293.

29. Ogoshi, A. 1987. Ecology and pathogenicity of anastomosis and intraspecific groups of Rhizoctonia solani Kühn. Annu. Rev. Phytopathol. 25:125-143.

30. Rinehart, T. A., Copes, W. E., Toda, T., and Cubeta, M. A. 2007. Genetic characterization of binucleate Rhizoctonia species causing web blight on azalea in Mississippi and Alabama. Plant Dis. 91:616-623.

31. Roberts, P. 1999. Thanatephorus. Pages 60-62 in: Rhizoctonia-Forming Fungi: A Taxonomic Guide. Herbarium, Royal Botanic Gardens, Kew, England.

32. Swofford, D. L. 1993. PAUP-a computerprogram for phylogenetic inference using maximum parsimony. J. Gen. Physiol. 102:A9.

33. Toda, T., and Hyakumachi, M. 2006. Heterokaryon formation in Thanatephorus cucumeris anastomosis group 2-2 IV. Mycologia 98:726736.

34. Vilgalys, R., and Cubeta, M. A. 1994. Molecular systematics and population biology of Rhizoctonia. Annu. Rev. Phytopathol. 32:135 155.

35. Warcup, J. H., and Talbot, P. H. B. 1967. Perfect states of Rhizoctonias associated with orchids. New Phytol. 66:631-641.

36. White, T. J., Bruns, T., Lee, S., and Taylor, J. 1990. Amplification of ribosomal RNA genes for molecular evolution studies. Pages 315-322 in: PCR Protocols: A Guide to Methods and Applications. M. A. Innis, D. H. Gelfand, J. J. Sninsky, and T. J. White, eds. Academic Press, San Diego, CA 